\title{
Comparison of the mechanical response of B400c and B450c dual phase steel bar categories, in long terms
}

\author{
Charis Apostolopoulos, Argyro Drakakaki \\ University of Patras, Greece \\ charrisa@upatras.gr,https://orcid.org/0000-0001-7414-8444 \\ drakakaki@upatras.gr, bttps://orcid.org/0000-0002-0448-2719
}

Alkiviadis Apostolopoulos
University of Ioannina, Greece
prothesis.apostolopoulos@gmail.com

Konstantinos Koulouris

University of Patras, Greece

kekoulouris@upnet.gr, bttps://orcid.org/0000-0003-2449-2751

\begin{abstract}
In this work, the effects of chloride-induced corrosion on tempcore B400c and B450c steel grades are evaluated, in terms of corrosion resistance and mechanical characteristics, after the performance of Tensile and Low Cycle Fatigue Tests. Both steel categories, characterized by high strength and high ductility, have been used in existing structures, indicating that they demonstrate different performance against the ascribed corrosion environments. B450c steel grade seems to preserve higher energy reserves, ensuring higher expectancy to the corresponding reinforced concrete structures. Additionally, due to buckling and buckling reversal, both steel grades demonstrate limited ductility at 4\%. Finally, when cyclically stresses occur, crack nucleation is taking place, at the areas where sulphides, FeS and MnS can be found, leading to sub-surface crack propagation, interacting with external pits.
\end{abstract}

KeYwORDS. Corrosion; Dual phase steel bars; B400c; B450c; Mechanical behaviour; Degradation of mechanical performance.

\section{OPEN \\ (e) ACCESS}

Citation: Apostolopoulos, Ch., Drakakaki, Arg., Apostolopoulos, Alk., Koulouris, K., Comparison of the mechanical response of $\mathrm{B} 400 \mathrm{c}$ and B450c dual phase steel bar categories, in long terms, Frattura ed Integrità Strutturale, 50 (2019) 548-559.

Received: 28.01 .2019

Accepted: 29.05.2019

Published: 01.10.2019

Copyright: (C) 2019 This is an open access article under the terms of the CC-BY 4.0, which permits unrestricted use, distribution, and reproduction in any medium, provided the original author and source are credited.

\section{INTRODUCTION}

einforced concrete has been the most popular material for more than a century. During these years, in an effort to upgrade the reliability of the structures, various steel grades, characterized by high strength and ductility, have been used as reinforcement. However, there is a plethora of degradation factors that may affect the performance 
and the reliability, not only of the material, but also of the whole structure [1]. Corrosion of steel reinforcement constitutes a major problem for reinforced concrete structures, as far as their durability is concerned, as it has also been mentioned by Almusallam [2]. Corrosion degradation is responsible for several issues, such as deterioration of both durability and service life of structures, resulting in premature failure. In recent years, the problem of the actual residual strength degradation of ageing reinforced concrete structures has attracted considerable attention, however it is far from being fully understood and even less resolved.

According to Apostolopoulos et al. [3], Papadakis [4], Capazucca[5], Diamond [6] and Alvarez et al. [7], this scenario becomes even worse when coastal environment, which is rich in chlorides, is combined with seismic phenomena. Cyclic loading, which is due to seismic activity, in conjunction with the pre-existing downgrade, which results from corrosion effect, leads to prompt deterioration of useful lifespan of structures, that face durability issues. Furthermore, cyclic loading, leads to a nonlinear response of the structures that face durability issues. Therefore, to predict the time dependent damage of corroded reinforced concrete structures under seismic loading it is necessary to consider the effects of material degradation, due to corrosion [8].

In the present work, the effects of chloride-induced corrosion on two different steel bar categories, B400c and B450c are evaluated, in terms of corrosion resistance and mechanical characteristics, before and after the corrosion process. The method that was used for the accelerated corrosion tests, was salt spray chamber and the mechanical tests performed for both steel bar categories were tensile tests and Low Cycle Fatigue Tests. The goal of the study was to highlight the differences among the two steel categories, as far as their mechanical performance and their resistance to corrosion is concerned. Given that both steel grades have been used in existing civil engineering structures, it is important to gain knowledge of their mechanical behavior and their vulnerability to corrosion factor, so as to be able to estimate their life expectancy.

\section{MATERIALS AND METHODS}

$\mathrm{F}$ or the goals of the present study, material of two different steel reinforcement categories B400c and B450c was used. The material, for both categories, was received from European factories and were produced by the same steel manufacturer using the "tempcore" method. The chemical composition, which is approximately the same for the two different steel bar categories. Specifically, both steel categories contain $0.22 \% \mathrm{C}, 0.05 \% \mathrm{P}, 0.05 \% \mathrm{~S}, 0.8 \% \mathrm{Cu}$ and $0.012 \%$ $\mathrm{N}$, while B450c has an additional $0.5 \%$ Ceq.

Two series of specimens, $500 \mathrm{~mm}$ and $250 \mathrm{~mm}$ long, of $16 \mathrm{~mm}$ nominal diameter, were organized for each steel grade. For comparison reasons, one more set of specimens of nominal diameter $12 \mathrm{~mm}$ and $500 \mathrm{~mm}$ long was prepared for B450c. Given that the goal of the present study is to evaluate the mechanical performance of both steel categories, before and after corrosion, salt spray chamber method was used for the performance of the corrosion tests. Exposure periods equal to 0 days, 45 days and 90 days were scheduled for each set of specimens. Consequently, each set was separated into three smaller groups, the first of which was only mechanically tested (Reference Specimens) while for the rest two groups corrosion took place prior to the mechanical tests.

Before the corrosion process, specimens were properly prepared. They were primarily cleaned in order to remove all the unwanted impurities from their surface. The configuration of equal surface areas, that would be exposed to the corrosive media, was necessary for comparison reasons. The exposed length for each specimen was equal to $20 \mathrm{~mm}$, while the rest part of the metal was covered with wax, to prevent corrosion (Fig.1).

The samples were exposed to the corrosion process and they were mechanically tested in Tensile and Low Cycle Fatigue (LCF) tests. Artificial corrosion tests were executed with the use of salt spray fog chamber - according to ASTM B117 [9].

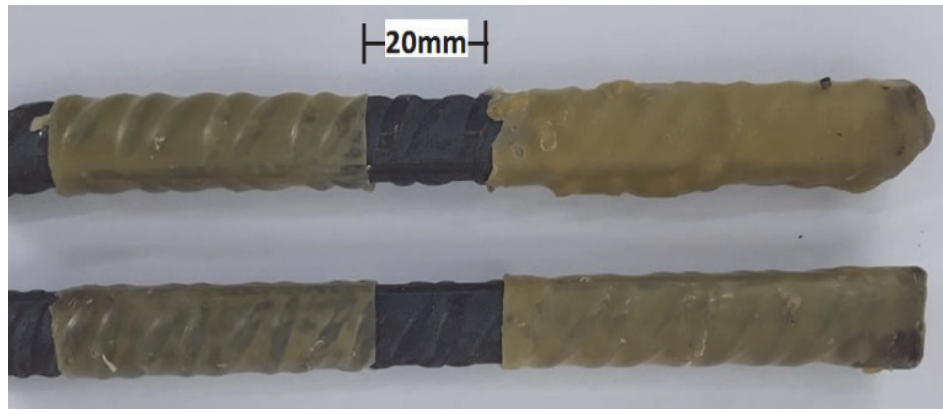

Figure 1: Preparation of the "short" specimens. 


\section{CORROSION TESTS - SALT SPRAY CHAMBER}

$\mathrm{F}$ or the corrosion process all the specimens were placed in a salt spray chamber (Fig.2). The corrosion tests were organized in accordance to ASTM B117-94 specification (directly exposed to the corrosive medium). The ASTM B117 [9] specification covers every aspect of the apparatus configuration, procedure and conditions required to create and maintain a salt spray (fog) testing environment. The selection of such a procedure for corroding the specimens, relies on the fact that the salt spray environment lies qualitatively closer to the natural coastal (rich in chlorides) conditions than any other accelerate laboratory corrosion test. In principle, the testing apparatus consists of a closed chamber in which a salted solution atomized by means of a nozzle, produces a corrosive environment of dense saline fog. In this particular study a special apparatus, model SF 450 (mode by Cand W. Specialist Equipment Ltd) was used. The salt solution was prepared by dissolving 5 parts by mass of sodium chloride $(\mathrm{NaCl})$ into 95 parts of distilled water ( $\mathrm{pH}$ range 6.5-7.2). The temperature inside the salt spray chamber was maintained at $35^{\circ} \mathrm{C}\left(+1.1-1.7^{\circ} \mathrm{C}\right)$.

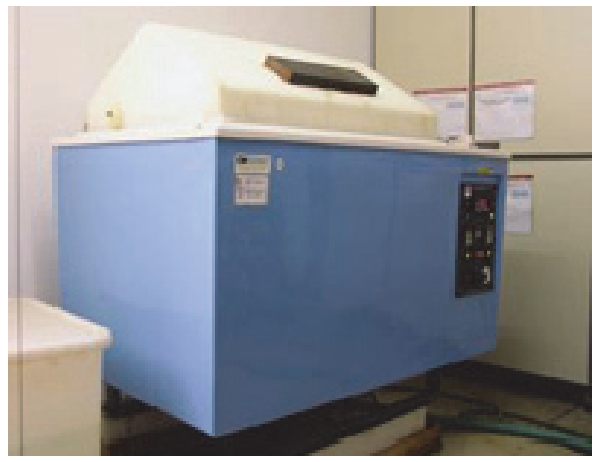

Figure 2: Salt spray fog chamber.

Additionally, in the present study, a severe exposure environment of wetting/drying (chloride ponding) was organized in order to achieve a better approach to the environmental conditions and to simulate the chloride exposures of marine structures under splash and tidal zones. Hence, it is widely known that that in reality, structures are subjected to wet and dry periods, rather than a constant relative humidity [10]. Chloride ponding application is in agreement with the simulating corrosion methods used in existing studies as well [11-13] and ensures conditions which are qualitatively closer to the natural. This is because during wetting, chloride solution penetrates a layer of the material; during the drying stage the evaporation front moves inwards and takes some of the chloride with it [10]. It is deducted in theory that atmospheric corrosion rate of metals can be accelerated by increasing the frequency of wet-dry cycling [12].

Consequently, the ponding cycles organized consisted of alternating 1.5 hour of exposure to wet conditions and 1.5 hour of dry conditions. Eight ponding cycles of wet/dry conditions were scheduled per day.

By the end of each exposure time, specimens were removed from the corrosive environment, washed with clean running water, to remove ant salt deposits from their surfaces and air dried. The corrosion products were removed from the surface of the specimen by means of a brittle brush, according to ASTM G1 specification [14]. The specimens were then weighted and the mass loss due to corrosion exposure was calculated as:

$$
x_{p}=\frac{m_{0}-m_{c}}{m_{0}} 100 \%
$$

Where $\mathrm{m}_{0}$ is the mass of uncorroded specimens and $\mathrm{m}_{\mathrm{c}}$ the reduced mass of the corroded specimens.

\section{MECHANICAL TESTS}

A fter the completion of the corrosion process the mechanical tests were organized. In Table 1 is given in detail the number of the specimens used in each case. According to Table 1, a total of 18 tensile tests and 134 Low Cycle Fatigue Tests was conducted for the goals of the present study. The differentiated number of the LCF tests, per strain, per steel category is owed to the fact that there were some additional tests that were invalid, the results of which are not included in the present paper. 


\begin{tabular}{|c|c|c|c|c|c|}
\hline $\begin{array}{c}\text { Steel } \\
\text { Category }\end{array}$ & $\begin{array}{l}\text { Nominal } \\
\text { Diameter }\end{array}$ & $\begin{array}{l}\text { Number of } \\
\text { Specimens }\end{array}$ & $\begin{array}{l}\text { Total length } \\
\qquad(\mathrm{mm})\end{array}$ & $\begin{array}{l}\text { Length exposed to } \\
\text { corrosion }(\mathrm{mm})\end{array}$ & Type of mechanical test \\
\hline $\mathrm{B} 400 \mathrm{c}$ & $\Phi 16$ & 9 & 500 & 20 & Tensile Tests \\
\hline $\mathrm{B} 400 \mathrm{c}$ & $\Phi 16$ & 20 & 250 & 20 & $\begin{array}{l} \pm 2.5 \% \text { strain-controlled } \\
\text { Low Cycle Fatigue Tests }\end{array}$ \\
\hline $\mathrm{B} 400 \mathrm{c}$ & $\Phi 16$ & 21 & 250 & 20 & $\begin{array}{l} \pm 4 \% \text { strain-controlled } \\
\text { Low Cycle Fatigue Tests }\end{array}$ \\
\hline B450c & $\Phi 16$ & 9 & 500 & 20 & Tensile Tests \\
\hline B450c & $\Phi 16$ & 20 & 250 & 20 & $\begin{array}{l} \pm 2.5 \% \text { strain-controlled } \\
\text { Low Cycle Fatigue Tests }\end{array}$ \\
\hline B450c & $\Phi 16$ & 22 & 250 & 20 & $\begin{array}{l} \pm 4 \% \text { strain-controlled } \\
\text { Low Cycle Fatigue Tests }\end{array}$ \\
\hline B450c & $\Phi 12$ & 25 & 250 & 20 & $\begin{array}{l} \pm 2.5 \% \text { strain-controlled } \\
\text { Low Cycle Fatigue Tests }\end{array}$ \\
\hline B450c & $\Phi 12$ & 26 & 250 & 20 & $\begin{array}{l} \pm 4 \% \text { strain-controlled } \\
\text { Low Cycle Fatigue Tests }\end{array}$ \\
\hline
\end{tabular}

Table 1: The specimens used for the goals of the current study.

The tensile tests were performed according to the ISO/FDIS 15630-1 [15] specification, using a servo-hydraulic MTS $250 \mathrm{KN}$ machine with a constant elongation rate of $2 \mathrm{~mm} / \mathrm{min}$. The mechanical properties, yield strength $\mathrm{Rp}$, ultimate strength $\mathrm{Rm}$, and uniform elongation Agt, were determined. It should be noted that Agt was measured according to the manual method described in the relevant standard (on a gauge length of $100 \mathrm{~mm}$, at a distance of $50 \mathrm{~mm}$ away from the fracture). Table 2 shows the minimum standards for medium and high ductility steel set by the EC2.

\begin{tabular}{cccc}
\hline Class & $\mathrm{Rp}(\mathrm{MPa})$ & Agt $(\%)$ & $\mathrm{Rp} / \mathrm{Rm}$ \\
$\mathrm{B} 400 \mathrm{c}$ & 400 & $\geq 7.5$ & $\geq 1.15<1.35$ \\
$\mathrm{~B} 450 \mathrm{c}$ & 450 & $\geq 7.5$ & $\geq 1.15<1.35$ \\
\hline
\end{tabular}

Table 2: Steel classes.

On the other hand, it is worth mentioning that LCF tests procedure for the cyclic mechanical behavior of steel bar is not included in the European production standards for reinforcements (EN 10080:2005). Only Spanish and Portuguese standards prescribe the execution of symmetrical tension/compression cycles for the production control of steel reinforcements, while the draft of new European standard for reinforcements (prEN 10080:2012) gives only some indications for the execution of LCF tests by Caprilli et al. [16-17].

In the present study, the LCF tests were performed using the above- mentioned servo- hydraulic MTS $250 \mathrm{kN}$ machine. Two free lengths, equal to $6 \mathrm{D}$ and $8 \mathrm{D}$ respectively, were tested for each steel category. The frequency used was equal to $2.5 \mathrm{~Hz}$ and strain imposed was equal to $\pm 2.5 \%$ and $\pm 4 \%$, in reference to their free length (either $6 \mathrm{D}$ or $8 \mathrm{D}$ ).

\section{RESULTS AND DISCUSSION}

lthough both B400c and B450c steel bar categories have been used in existing structures, several worth mentioning
differences can be reported, as far as their mechanical performance and their corrosion resistance are concerned,
in long term. In Tables 3 and 4 are presented the results concerning both the mass loss percentages and the mechanical properties of the long specimens $(500 \mathrm{~mm})$, of $16 \mathrm{~mm}$ nominal diameter. Taking into consideration the data of Tables 3 and 4 , it is evident that both steel grades demonstrate similar vulnerability to the corrosion factor. As far as the mechanical characteristics are concerned, B400c recorded 6.5\% drop of yield strength against 5.7\% of B450c, after the 90 days of 
exposure to the corrosive environment. On the contrary, for the same exposure period, elongation of B450c steel was diminished about $77.12 \%$ against $69.87 \%$ of B $400 \mathrm{c}$ category. However, it is remarkable, that plastic deformation recorded for both steel categories, after the completion of the first 45 days, was lower than the value that Eurocode 2 requires, which is equal to $7.5 \%$. The corresponding results of LCF tests are presented in Figs.3 and 4.

\begin{tabular}{cccccc}
\hline Steel Grade & TCorr (Days) & Mass Loss $(\%)$ & $\mathrm{Rp}(\mathrm{MPa})$ & $\mathrm{Rm}(\mathrm{MPa})$ & Agt $(\%)$ \\
B400c & 0 & 0 & 437 & 549 & 15.6 \\
B400c & 0 & 0 & 435 & 548 & 16.0 \\
B400c & 0 & 0 & 433 & 550 & 15.3 \\
AVERAGE & & 0 & 435 & 549 & 15.6 \\
B400c & 45 & 5.9 & 435 & 518 & 6.3 \\
B400c & 45 & 5.5 & 431 & 520 & 5.7 \\
B400c & 45 & 4.8 & 429 & 520 & 6.3 \\
AVERAGE & & 5.4 & 432 & 519 & 6.1 \\
B400c & 90 & 8.5 & 400 & 497 & 5.2 \\
B400c & 90 & 9.7 & 414 & 494 & 4.1 \\
B400c & 90 & 9.6 & 408 & 488 & 4.7 \\
AVERAGE & & 9.3 & 407 & 493 & 4.7 \\
\hline
\end{tabular}

Table 3: Mass Loss Results and Mechanical Characteristics of B400c steel bar samples, of 16mm nominal diameter before and after their exposure to corrosive conditions

\begin{tabular}{cccccc}
\hline Steel Grade & TCorr (Days) & Mass Loss $(\%)$ & $\mathrm{Rp}(\mathrm{MPa})$ & $\mathrm{Rm}(\mathrm{MPa})$ & Agt $(\%)$ \\
B450c & 0 & 0 & 541 & 651 & 11.4 \\
B450c & 0 & 0 & 532 & 644 & 12.3 \\
B450c & 0 & 0 & 536 & 649 & 11.7 \\
AVERAGE & & 0 & 536.4 & 648 & 11.8 \\
B450c & 45 & 6.0 & 528 & 614 & 4.6 \\
B450c & 45 & 6.2 & 534 & 613 & 4.1 \\
B450c & 45 & 6.1 & 533 & 617 & 4.3 \\
AVERAGE & & 6.1 & 532 & 615 & 4.3 \\
B450c & 90 & 11.2 & 512 & 566 & 2.4 \\
B450c & 90 & 11.3 & 509 & 581 & 2.7 \\
B450c & 90 & 10.1 & 496 & 575 & 3.0 \\
AVERAGE & & 9.3 & 506 & 574 & 2.7 \\
\hline
\end{tabular}

Table 4: Mass Loss Results and Mechanical Characteristics of B450c steel bar samples, of $16 \mathrm{~mm}$ nominal diameter, before and after their exposure to corrosive conditions.

Examining the performance of both steel categories, in $\pm 2.5 \%$ deformation (where buckling effects are relatively mild), reference B450c steel achieves $22.4 \%$ higher life cycle (67cycles) than the reference B400c steel (52 cycles). However, after 45 and 90 days of exposure to the corrosive conditions, life cycles of both steel categories are approximately equal.

According to the results presented in Figs.3 and 4, it seems that although corrosion factor is responsible for similar mass loss percentages in both steel categories, however they demonstrate different performance under the cyclic testing. This fact is owed to the different thickness of the martensite layer of the two steel grades [18]. Precisely, B400c steel bar category recorded a great drop, of more than $60 \%$, on the number of cycles up to failure until the first 45 days of exposure to the 
aggressive conditions, for both deformations imposed $(\Delta \varepsilon= \pm 2.5 \%$ and $\Delta \varepsilon= \pm 4 \%)$ and for both free lengths defined (6D and 8D). Whereas, consistency was recorded for the next 45 days, up to the completion of the exposure period of 90 days. On the other hand, B450c steel grade, recorded an initial drop on its cyclic life, the mean value of which was higher than $50 \%$ for both deformations $(\Delta \varepsilon= \pm 2.5 \%$ and $\Delta \varepsilon= \pm 4 \%)$ and for both free lengths defined (6D and 8D) and an extra dron higher than $12.5 \%$ up to the 90 days, for $\Delta \varepsilon= \pm 2.5 \%$ (for both free lengths $6 \mathrm{D}$ and $8 \mathrm{D}$ ).

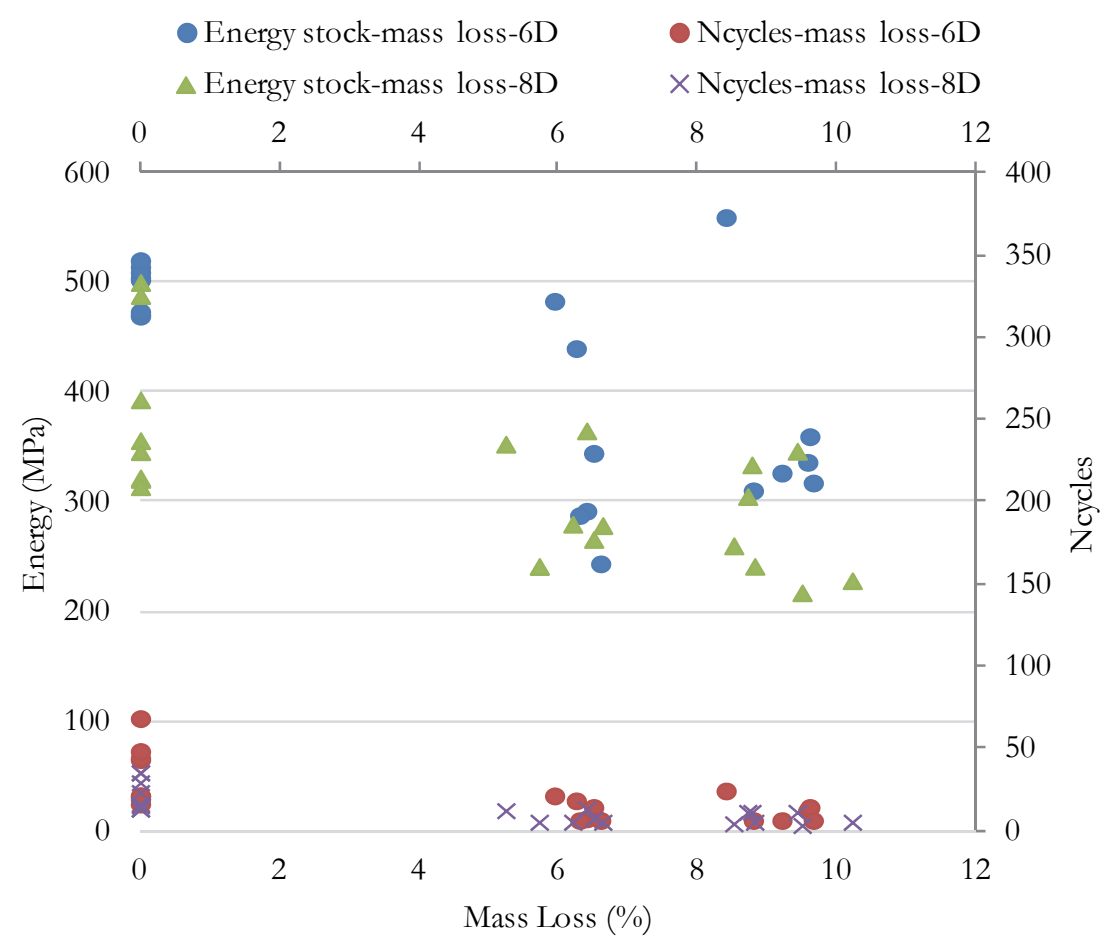

Figure 3: A graphical depiction of energy stocks and number of cycles of the B400c (Ф16) specimens tested in LCF, in reference to their corresponding mass loss, before and after their exposure to corrosive conditions.

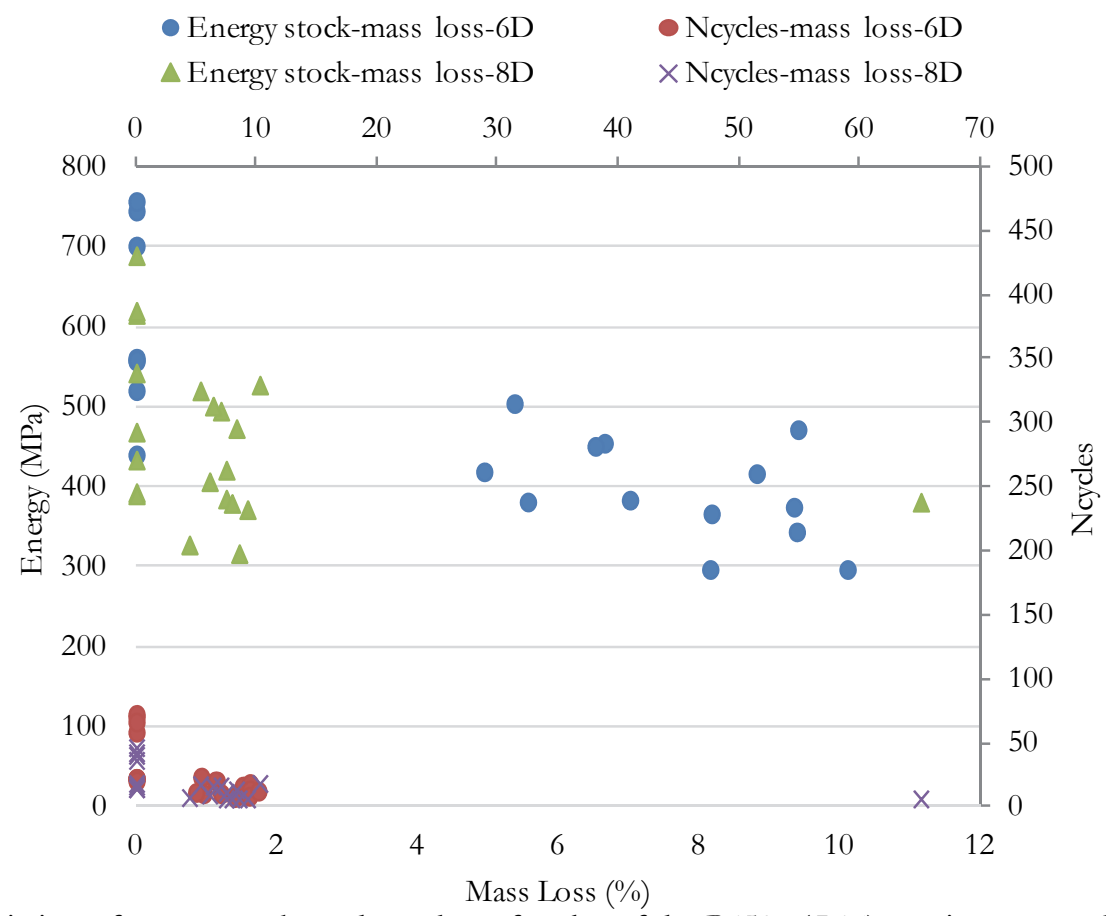

Figure 4: A graphical depiction of energy stocks and number of cycles of the B450c (Ф16) specimens tested in LCF, in reference to their corresponding mass loss, before and after their exposure to corrosive conditions. 
Additionally, due to buckling and buckling reversal, the material's ductility especially at 4\% is particularly limited. Explicitly, the free length of the specimen strongly influences the results of the experimental tests, since buckling phenomena due to compression axial loads can lead to premature unexpected failures of the rebars (Fig.5); in order to avoid this problem, actual standards for reinforced concrete constructions (EN 1998-1:2005, D.M. 14/01/2008) prescribe the adoption of opportune limits for the free length of reinforcements between stirrups, that shall be lower than 6 or 8 times the diameter for buildings respectively designed in high, medium or low ductility class. For comparison reasons, a few more LCF tests were performed on reference B450c steel bar specimens, of $12 \mathrm{~mm}$ nominal diameter. The corresponding results are presented in Fig.6.

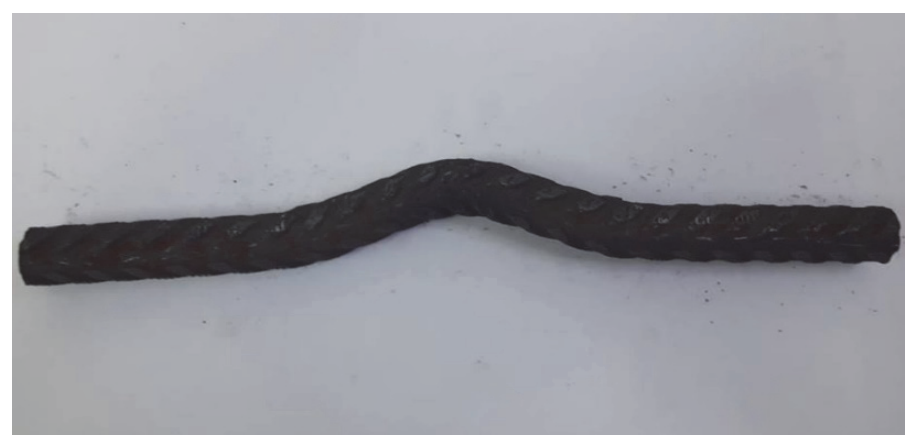

Figure 5: Buckling effect on a tested rebar.

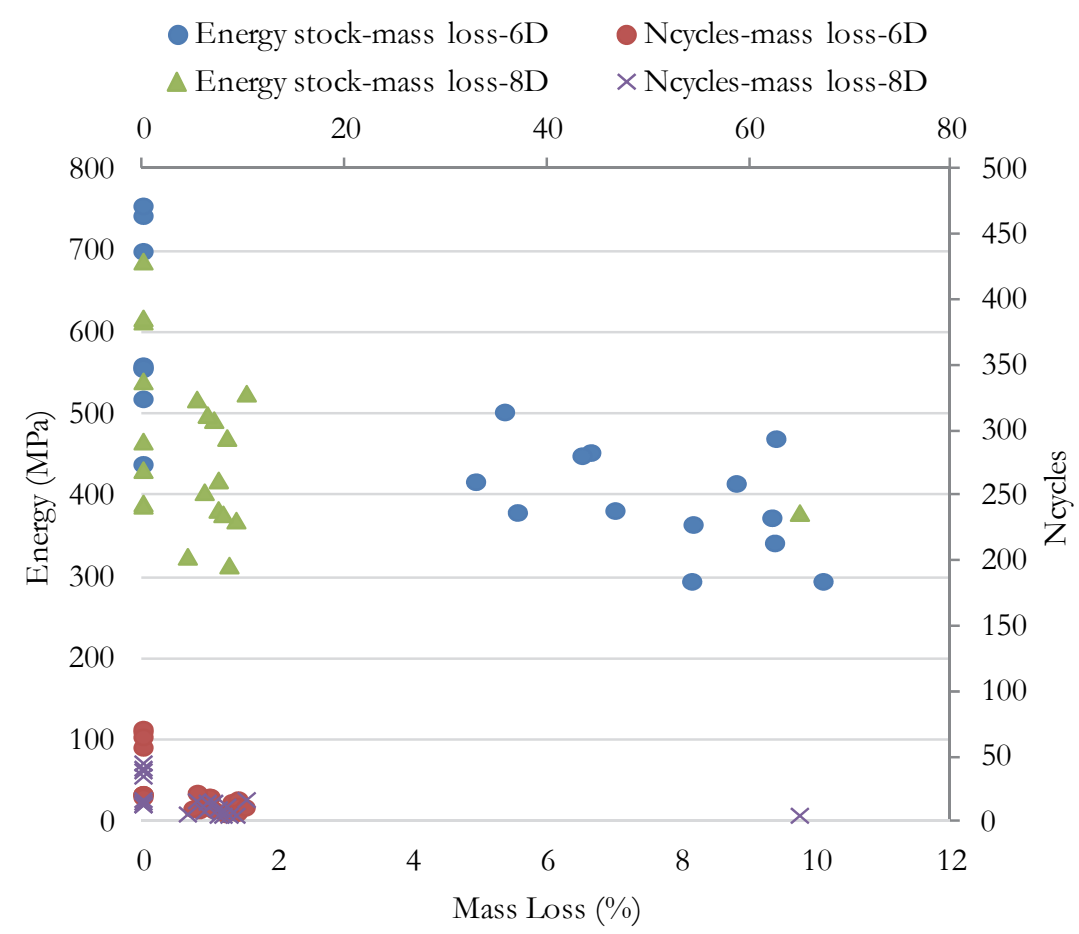

Figure 6: A graphical depiction of energy stocks and number of cycles of the B450c (Ф12) specimens tested in LCF, in reference to their corresponding mass loss, before and after their exposure to corrosive conditions

Comparing the results of Fig.4, with the corresponding results of Fig.6, where the same steel category- but with different nominal diameter- was used, it seems that specimens with $12 \mathrm{~mm}$ diameter record lower mass loss percentages. This is owed to the fact that corrosion process, that is conducted in the salt spray chamber, is a method that mainly affects the external surface of the material. In the case of $16 \mathrm{~mm}$ nominal diameter, the spread of the exposed surface is greater than in the case of $12 \mathrm{~mm}$, and it is a fact that results in a greater surface attack. This remark, in combination with the existing knowledge, related to the differential aeration corrosion phenomenon, can sufficiently explain that the rate of the electrons flow- and therefore the corrosion rate- depend on the volume of the exposed material as well as the volume of the protected (not exposed to the aggressive conditions) part of the steel reinforcement. 
Additionally, specimens of $12 \mathrm{~mm}$ nominal diameter record higher performance under LCF testing, than the corresponding specimens of $16 \mathrm{~mm}$ nominal diameter. This annotation is closely associated with the lower corrosion damage (e.g. mass loss rate or/ and pitting severity) recorded.

Combining the results of the tensile and the LCF tests, a correlation with real structures can take place. Analytically, it is a fact, that during strong earthquakes, yielding structures are subjected to increased number of cycles into the inelastic range and the accumulated damage may significantly affect their overall performance. However, little attention has been devoted by the research community on the combined effect of corrosion and LCF on steel reinforcement, since each one of these factors affects the rebar durability and performance and shortens the life expectancy of structures [19-24]. It is known though, that besides external overt damage, more internal and subcutaneous phenomena are realized. At those areas, plethora of MnS and FeS compounds (potential sites of corrosion initiation or for the formation of corrosion paths) can be detected. Synergy of both internal and external corrosion factor, may result in premature and unexpected failure of the material [25].

In an effort to further investigate the degradation phenomena, which are related to the internal downgrading of the material, several SEM and EDX analyses took place. Prior to tensile testing, the cross sections of reference rebars were examined under scanning electron microscope, after having been polished to surface roughness of $\mathrm{Ra}<0.8 \mu \mathrm{m}$.

Figs. 7 and 8 illustrate the SEM and EDX analyses in reference B400C, $\Phi 16$ steel, without tension. The area depicted is about $1300 \mu \mathrm{m}$ from the outer surface within the martensitic zone.

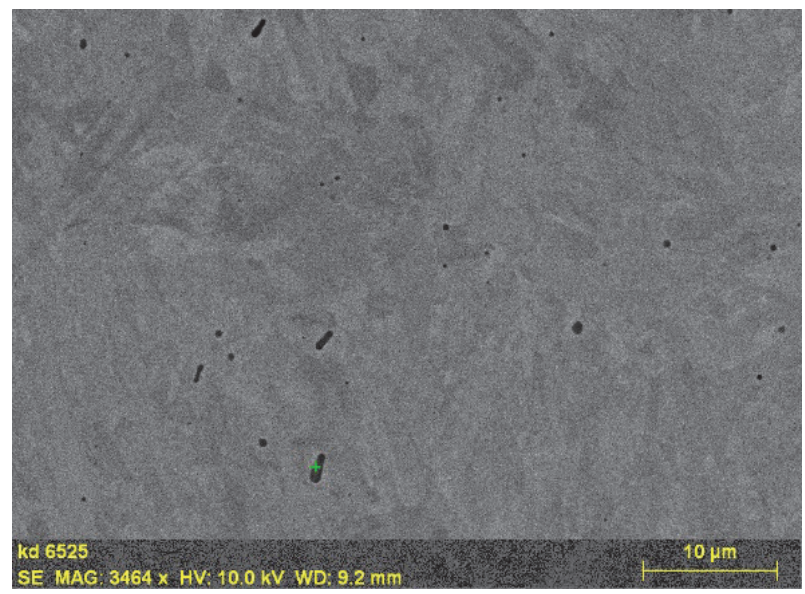

Figure 7: SEM analysis in reference B400C, Ф16 steel, without tension.

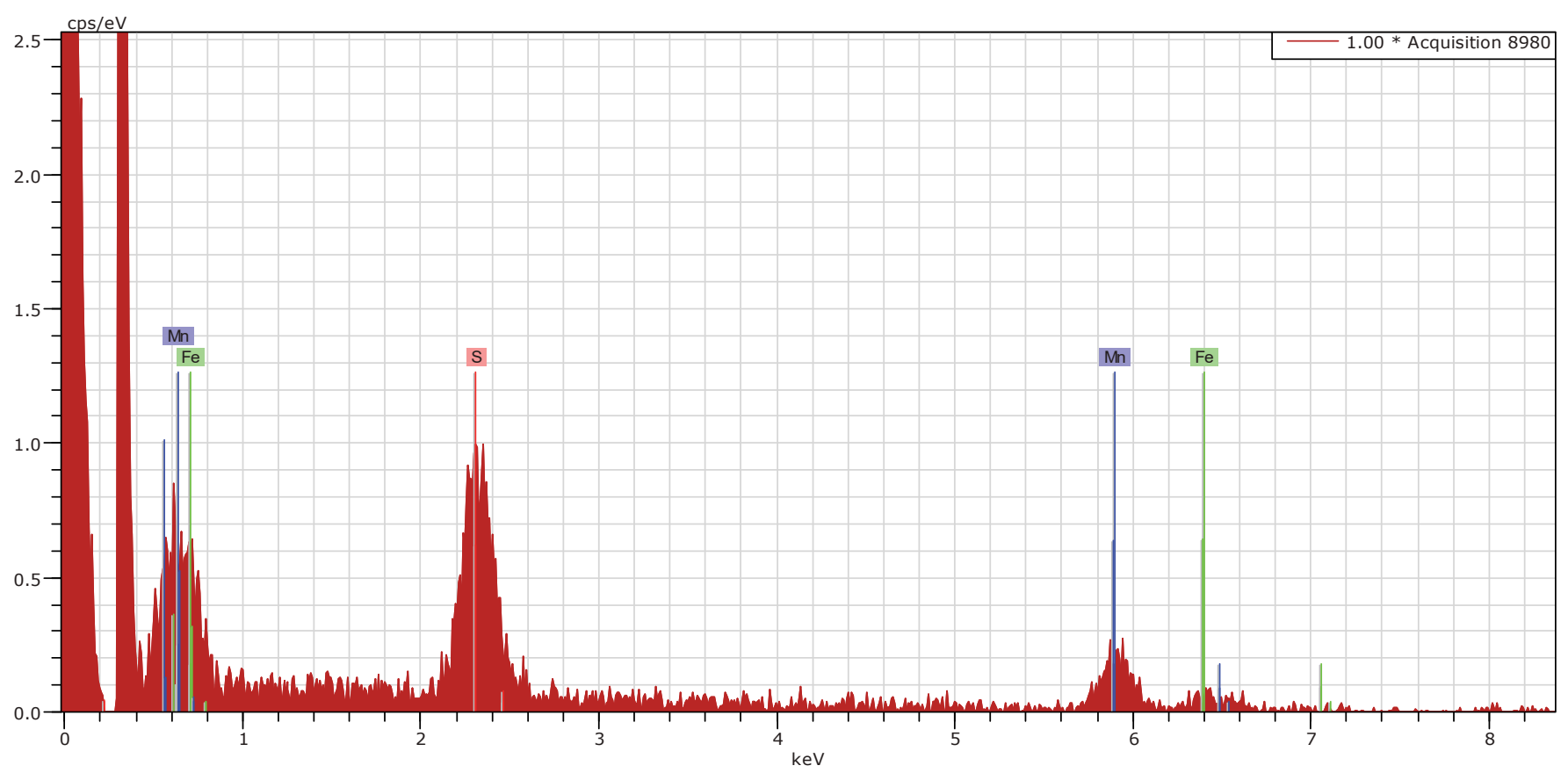

Figure 8: EDX analysis in reference B400C, Ф16 steel, without tension. 
Figs.9 and 10 illustrate the SEM and EDX analyses in a corroded B400C, 116 sample, after tensile test. Moreover, through $\mathrm{X}$ rays' diffusion, the appearance of pores was obvious at the external martensitic surface and at the same area high sulfide concentration was noticed. This fact increased the requirements for damage expansion at the inner area of the external surface (skin). Fig.11, which has been taken from study [26], that processes on the same rebar group, presents a SEM analysis of a longitudinal cut in the fracture region in a non - corroded B450c specimen after tensile test.

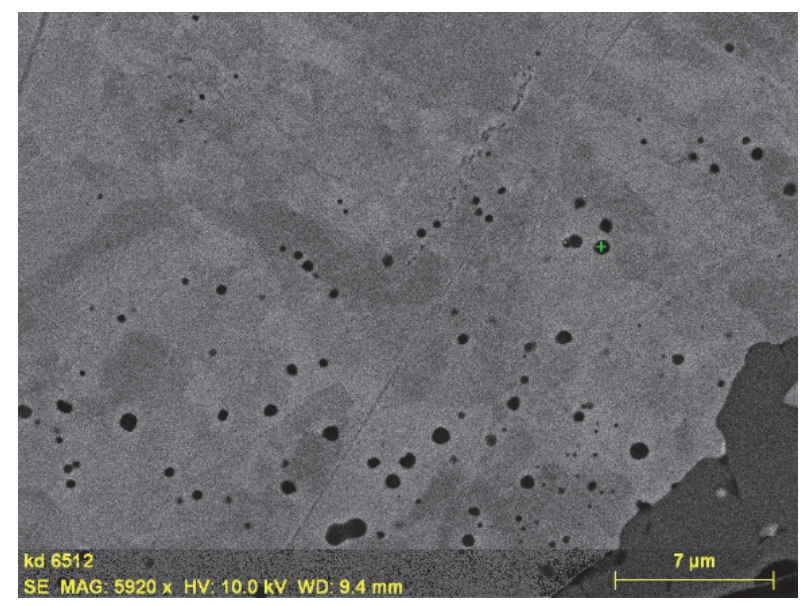

Figure 9: SEM analysis in a corroded B400C, $\Phi 16$ sample, after tensile test.

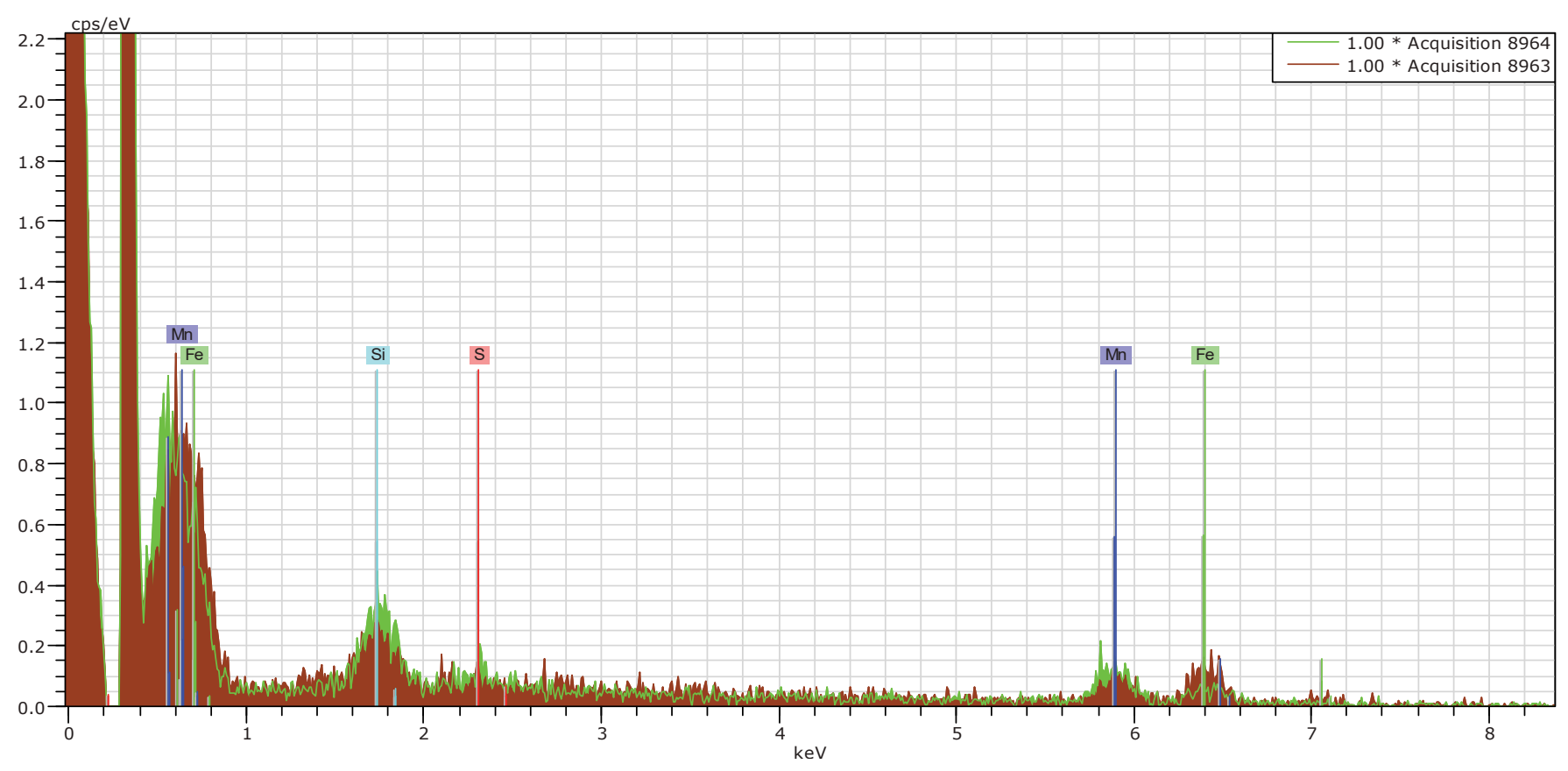

Figure 10: EDX analysis in a corroded B400C, Ф16 sample, after tensile test.

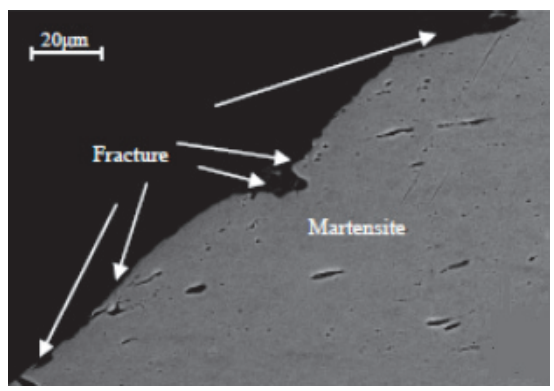

Figure 11: Fracture surface (longitudinal cross section) of a non corroded specimen B450c [26]. 
Figs.12 and 13 present a SEM and an EDX analysis of a longitudinal cut in the fracture region in a noncorroded specimen after tensile test (B450c). According to these findings, the area depicted is rich in $\mathrm{MnS}$ and FeS compounds, phenomenon which gradually leads to a local decomposition, and inevitably to the failure of the material.

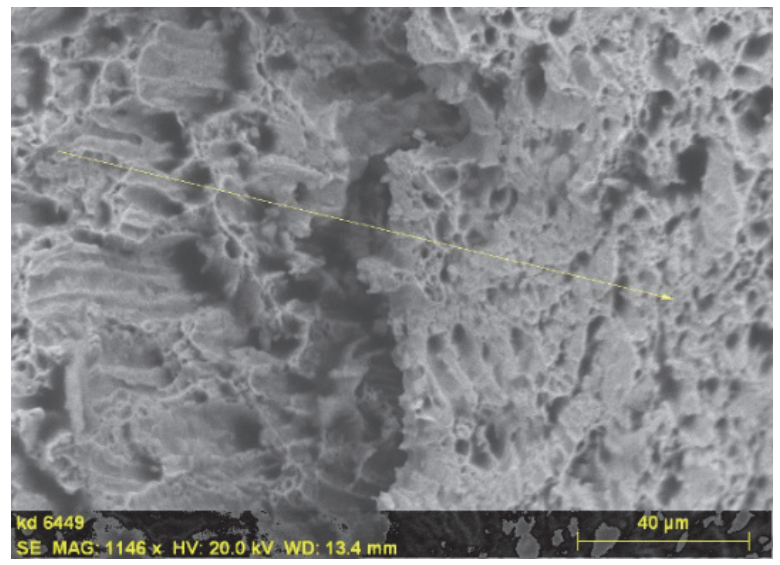

Figure 12: SEM analysis of the fracture region in a noncorroded specimen after tensile test (B450c).

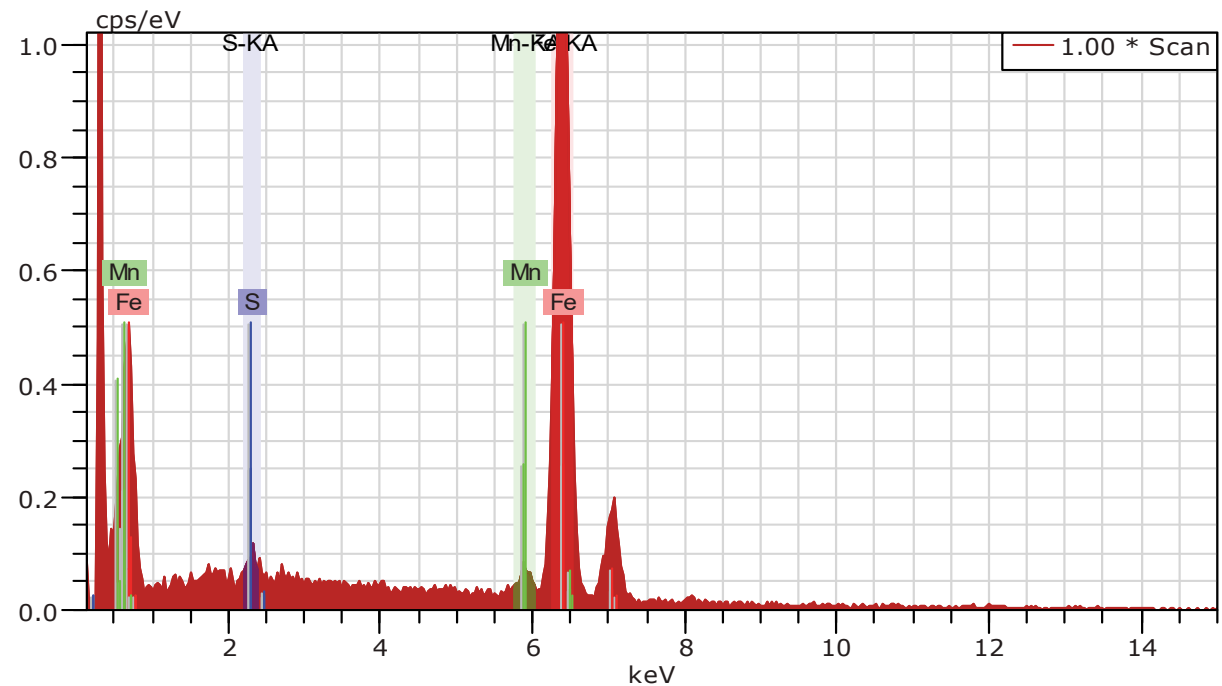

Figure 13: EDX analysis of the fracture region in a reference specimen after tensile test (B450c).

It is very likely that the adsorption of $\mathrm{Cl}$ - ions in and around the strained regions of a MnS-Fe interface triggers the anodic dissolution of $\mathrm{Fe} 2+$ ions. It is important to reemphasize here that $\mathrm{Cl}$ - ions are not involved in redox reactions but catalyze the anodic processes by adsorbing on the surfaces around the MnS inclusions and by chasing away the conduction electrons of the strained matrix, which results in the anodic dissolution of iron from these regions as depicted in Fig.14 [27].

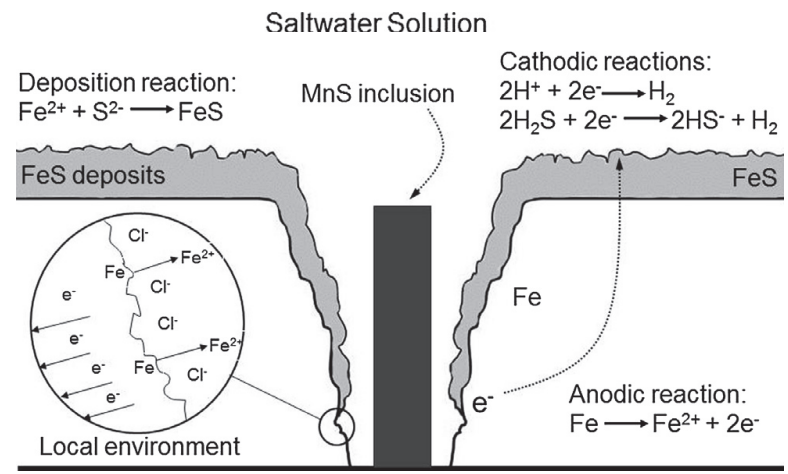

Figure 14: Corrosion mechanisms surrounding a MnS inclusion: refer to Avci et al.[27] for details. 
From a structural point of view, dissolved MnS sites and porosity represent high stress raisers, which upon loading can lead to the development of microcracks. These phenomena within the martensitic zone, near the location of surface pitting, result in local distuption of the material and a possible conjunction of extended imperfections with the surface pits. In these locations, the local distuption of the material is a crucial factor of its mechanical behavior since during the axial load an intense stress concentration is developed and the subsequent crack propagation is inevitable and rapid [8]. Rapid depletion of the ductility or even failure may occur in high strength and ductility dual phase steel bars, due to the combination of interior and exterior damage phenomena under strong stresses.

Consequently, an additional purpose of this study is to highlight the significance of the corrosion factor on the mechanical performance of the dual phase steel bars and to estimate the degradation of its mechanical properties, which is the result of the cooperation of the internal and the external damage, under those hazardous circumstances [25].

The results of the mechanical tests confirmed that corrosion, due to chloride ions, is one of the main degradation factors of steel reinforcement.

\section{CONCLUSIONS}

he conclusions of the present study can be summarized as follows:

- Steel bar category B450c recorded slightly higher mass loss percentages than B400c steel class, a fact that demonstrates that the first category is more vulnerable to corrosion.

- In both steel categories, a slight mechanical degradation was recorded, in terms of yield and maximum strength, while ductility and dissipated energy were dramatically diminished.

- Due to buckling and buckling reversal, materials demonstrate limited ductility especially at 4\%.

- When cyclically stresses occur, sulphides, FeS and MnS sites will host crack nucleation leading to sub-surface crack propagation, which interact with external pits. The case becomes very complex in terms of analysis, especially under fully reverse loading and high plastic strain levels leading to buckling

- Among two specimens of the same steel class, the one with smaller nominal diameter records higher performance against LCF tests.

- The areas with $\mathrm{MnS}$ compounds present a significant development under the presence of $\left(\mathrm{Cl}^{-}\right)$ions, which combined with the occurrence of other impurities, as well as pits at the surface of steel, may inevitably induce mechanical stress concentration during the tensile loading

- Therefore, the mechanical degradation of precorroded steels that were examined can result from the synergy of mass loss effect, external pitting, and a variety of inevitable side effects from regions with $\mathrm{MnS}$ compounds within the martensitic zone.

- Examining the performance of both steel categories under LCF tests, it seems that reference B450c steel has grater life cycle and higher energy stocks than the reference B $400 \mathrm{c}$ steel. However, when both categories record $5 \%-10 \%$ mass loss, under corrosion conditions, life cycles of both steel categories are approximately equal.

\section{ACKNOWLEDGEMENTS}

7 he present work has been implemented within the framework of the European Research project Rusteel (Effect of corrosion on low-cycle (seismic) fatigue-Behaviour of high strength steel reinforcing bars) (2008-2012), Project funded by RFCS - Contract No. RFSR-CT-2009-00023

\section{REFERENCES}

[1] Apostolopoulos, C.A., Papadakis, V.G., (2008). Consequences of steel corrosion on the ductility properties on reinforcement bar, Construction and Building Materials, 22, pp. 2316-2324

[2] Almusallam, A., (2001). Effect of degree of corrosion on the properties of reinforcing steel bars, Construction and Building Materials, 15(8), pp. 361-368

[3] Apostolopoulos, Ch., (2007). Mechanical behavior of corroded reinforcing steel bars S500s tempcore under low cycle fatigue, Construction and Building Materials, 21, pp.1447-1456

[4] Papadakis, V.G., (1999). Supplementary cementing materials in concrete-activity, durability and planning, Danish Technological Institute Concrete Center 
[5] Capazucca, R., (1995). Damage to reinforcement concrete due to reinforcement corrosion, Constr. Build. Mater., 9, pp. 295-303.

[6] Diamond, S.E, (1986). Chloride concentration in concrete pore solutions resulting from calcium and sodium chloride admixtures, Com Concr. Aggr., 8, pp. 97-102.

[7] Alvarez, M.G., Galvele, J.R. (1984). The mechanisms of pitting of high purity iron in $\mathrm{NaCl}$ solutions, Corros. Sci., 24, pp.27-48.

[8] Afsar, E. and Kashani, M.M., (2017), Exploring the impact of chloride-induced corrosion on seismic damage limit states and residual capacity of RC structures, Structure and Infrastructure Engineering, 14 (6), pp.714-729.

[9] ASTM B 117-94. (1995) Standard practice for operating salt (fog) testing apparatus. In: Annual Book of ASTM standards, section 3, Metal test Methods and analytical Procedures. Philadelphia, USA: West Conshohocken, ASTM.

[10] Quanmin, Ma., Sreejith, V., Nanukuttan P.A, Basheer, M., Bai, Y. and Yang, Ch. (2016). Chloride transport and the resulting corrosion of steel bars in alkali activated slag concretes, Materials and Structures, 49, pp. 3663-3677.

[11] Angst, U.M. and Elsener, B. (2017). The size effect in corrosion greatly influences the predicted life span of concrete infrastructures, Applied Sciences and Engineering,.3.

[12] Vera Cruz, R.P., Nishikata, A. and Tsuru, T. (1998). Pitting corrosion mechanism of stainless steels under wet-dry exposure in chloride-containing environments, Corrosion Science, 40, pp. 125-139.

[13] Obla, K.H., Lobo, C.L and Kim, H. (2016). Tests and Criteria for Concrete Resistant to Chloride Ion Penetration, ACI Materials Journal, pp. 621-631.

[14] ASTM G1-90 (1995). Standard practice for Preparing, Cleaning and Evaluating Corrosion Test Specimens. In: Annual Book of ASTM standards, section 3, Metal test Methods and analytical Procedures. Philadelphia, USA: West Conshohocken.

[15] UNI EN ISO 15630-1:2010, Steel for the reinforcement and pre-stressing of concrete. Test methods. Part 1: Reinforced bars, wire rod and wire. Eur. Com Stand

[16] Caprili, S. and Salvatore, W., (2015). Cyclic behaviour of uncorroded and corroded steel reinforcing bars. Construction and Building Materials, 76, pp.168-186.

[17] Apostolopoulos, Alk. and Matikas, T., (2018). The impact of corrosion and inelastic buckling on low cycle fatigue life of steel bars, Procedia Structural Integrity, 10, pp. 49-58.

[18] Salvatore, W., Caprili, S., Braconi, A., Finetto, M., Bianco, L., Ascanio, C., Moersch, J., Apostolopoulos, C., Ferreira Pimenta, G., (2014). Effects of corrosion on low-cycle fatigue (seismic) behavior of high-strength steel reinforcing bars (Rusteel), Grant Agreement RFSR-CT-2009-00023, Directorate-General for Research and Innovation.

[19] Ma, S.Y.M., Bertero, V.V. and Popov, E.P., (1976). Experimental and Analytical Studies on the Hysteretic Behaviour of Reinforced Concrete Rectangular and T-Beams. Earthquake Eng. research report 76 (No.2), Berkeley: Univ. of California

[20] Yoshaki, T., (1983). Proceedings of Academical Lectures of JAS. Tokyo, 606.

[21] Shigeru, H., (1995). Research report, Retrofitting of reinforced concrete moment Resisting Frames, supervised: Park, R., Tanaka, H., ISSN0110-3326

[22] Clementa, G.G., (2002). Testing of selected metallic reinforcing bars of extending the service life of future concrete bridges, Fin. report, Virginia Transport, Charlot, VA, Research Council, VTRC 03-A7.

[23] Krawinkler, H., (1987). Performance assessment of steel components. Earthquake Spectra 3, 27.

[24] Kasiraj, I. and Yao, J.T.P., (1969). Fatigue damage in seismic structures. Journal of the Structural Division (ASCE) 95, 1673.

[25] Apostolopoulos, Ch., Drakakaki, Arg., Apostolopoulos, Alk., Matikas, T., Rudskoi, A.I. and Kodzhaspirov, G., (2017). Characteristic defects-Corrosion Damage and Mechanical Behavior of Dual phase rebar, Materials Physics and Mechanics, 30, pp.1-19.

[26] Apostolopoulos, C.A, Diamantogiannis, G and Apostolopoulos, A.C, (2015). Assessment of the mechanical behavior in dual phase steel B400c, B450c and B500b in marine environment, Journal of Materials in Civil Engineering, 28(2), 10.1061/ (ASCE)MT.1943-5533.0001271, 04015097.

[27] Avci, R., Davis, B.H., Wolfenden, M.L., Beech, I.B., Lucas, K. and Paul, D. (2013), Mechanism of MnS-mediated pit initiation and propagation in carbon steel in an anaerobic sulfidogenic media, Corrosion Science, 76, pp.267-274. 